\title{
Novel Helicobacter species isolated from rhesus monkeys with chronic idiopathic colitis
}

\author{
JAMES G. FOX, LAWRENCE HANDT*, SHILU XU, ZELI SHEN, FLOYD E. DEWHIRST†, \\ BRUCE J. PASTER $\dagger$, CHARLES A. DANGLER, KEN LODGE*, SHERRI MOTZEL* and \\ HILTON KLEIN* \\ Massachusetts Institute of Technology, Cambridge, MA, *Merck Research Laboratories, West Point, PA and \\ †Forsyth Institute, Boston, MA, USA
}

\begin{abstract}
Chronic, idiopathic diffuse colitis is a well recognised clinical and pathological entity in captive rhesus monkeys. Six rhesus monkeys were diagnosed with clinically debilitating, chronic diarrhoea. Histologically, colonic tissues were characterised as chronic, moderate to severe colitis and typhlitis, with diffuse mononuclear inflammation of lamina propria, reactive lymphoid hyperplasia and multifocal micro-abscesses. Colonic tissues were cultured for Salmonella spp. and Shigella spp.; all results were negative. Samples were negative for Clostridium difficile A and B toxins, and special stains of colonic tissue for acid-fast bacteria were also negative. The six diarrhoeic monkeys tested gave negative results for serum IgG antibodies to herpes B virus, STLV, SRV and SIV. Colonic tissue from the six diarrhoeic and two clinically normal monkeys with histologically confirmed colitis from the same colony were also subjected to micro-aerobic culture. Micro-aerobic cultures from all eight monkeys incubated at $37^{\circ} \mathrm{C}$ and $42^{\circ} \mathrm{C}$ revealed pinpoint or spreading colonies on antibiotic-containing media. Bacteria were identified as gramnegative, oxidase positive and urease negative. Of the nine strains characterised biochemically, two separate biotypes (corresponding to different species by 16S rRNA analysis) were identified. One biotype (type 1), from non-diarrhoeic monkeys and the second biotype (type 2) from diarrhoeic animals with subclinical chronic colonic inflammation, differed by catalase activity, ability to reduce nitrate to nitrite and sensitivity to cephalothin. Complete 16S rRNA analysis of five of the nine strains characterised biochemically indicated that the organisms isolated were two novel Helicobacter spp. By electron microscopy, these novel helicobacters had spiral morphology with bipolar sheathed flagella. This is the first report describing the isolation of novel Helicobacter spp. from inflamed colons of rhesus monkeys. Studies are needed to determine whether these novel Helicobacter spp. play a causal role in the initiation and progression of chronic colitis in macaques. Further microbiological and histological analysis of this chronic idiopathic colitis syndrome in macaques may prove useful in understanding the aetiology and pathogenesis of inflammatory bowel disease in man.
\end{abstract}

\section{Introduction}

Chronic idiopathic colitis in young rhesus monkeys (Macaca mulatta) is a well recognised clinical syndrome in animals maintained in captivity [1]. Monkeys with this disease have a debilitating persistent diarrhoea accompanied by progressive weight loss and dehydration. Histologically, the inflammatory lesions in

Received 23 Aug. 2000; revised version received 22 Oct. 2000; accepted 2 Nov. 2000.

Corresponding author: Dr J. G. Fox (e-mail: jgfox@mit.edu). the colon are characterised by lymphoplasmacytic infiltration, crypt epithelial hyperplasia, goblet cell depletion, presence of multifocal crypt abscesses and mucosal erosion and ulceration. The pathology of this disease mimics many characteristics of ulcerative colitis in man and cotton top tamarins (CTT) [2]. Approximately $50 \%$ of colony-maintained CTT develop active colitis, with the disease progressing to adenocarcinoma in $25-40 \%$ of those primates with clinically recognised colitis [3-5]. In CTT, there are supportive data which suggest that both environmental and infectious agents may be responsible for the disease $[4,6]$. 
A novel Helicobacter sp. from inflamed colons of CTT was recently isolated and characterised and it was proposed that this microbe could be linked to the development of inflammatory bowel disease (IBD) in this species [2]. A specific serological response to this novel Helicobacter sp. has also been reported in CTTs with chronic colitis [7]. Helicobacter spp. are capable of inducing typhlocolitis in both immunocompetent and immune dysregulated mice and rats [8-11]. Furthermore, $H$. cinaedi and $H$. fennelliae have been isolated from inflamed colonic tissue of diarrhoeic, immunocompromised human patients [12]. When inoculated into pig-tailed macaques ( $M$. nemestrina), these organisms produce diarrhoea and bacteraemia [13].

Although the gastric helicobacters, H. pylori and $H$. heilmannii, are increasingly recognised in the gastric mucosa of macaques and organisms with spiral morphology have been noted by light and electron microscopy on surfaces of colonic epithelia in normal rhesus monkeys, enteric Helicobacter spp. have not been isolated previously from macaque monkeys [14]. Given the increasingly recognised important role of gastric and enterohepatic helicobacters in causing gastrointestinal disease, it was hypothesised that novel Helicobacter spp. may also be present in inflamed colons of rhesus monkeys with chronic idiopathic colitis. This study examined a group of rhesus monkeys with protracted diarrhoea and chronic colitis for the presence of Helicobacter spp.

\section{Materials and methods}

\section{Clinical history}

The rhesus monkeys were received at the research facility weighing between 2 and $4 \mathrm{~kg}$. Before their arrival they had been treated with enrofloxacin $5 \mathrm{mg} / \mathrm{kg}$ i.m. once daily for 10 days for prophylactic treatment of subclinical shigella infections. All rhesus monkeys were housed individually after arrival and underwent an initial standardised conditioning regimen. All were treated with praziquantel $(5.7 \mathrm{mg} / \mathrm{kg}$ i.m. once) and ivermectin (100 $\mu \mathrm{g} / \mathrm{kg}$ i.m. once) during this period. The diarrhoea in the six clinically affected animals was characterised by frequent, low-volume liquid faeces occasionally containing blood. Eventually, the monkeys lost weight and terminally became anorexic and dehydrated. The clinical signs of three treated animals improved after antimicrobial treatment, but they continued to have intermittent diarrhoea until their death and necropsy. Two other monkeys without diarrhoea were also assessed for presence of Helicobacter spp. in colonic tissue.

\section{Gross necropsy and microbial analysis}

A gross necropsy was conducted on the six diarrhoeic monkeys, with collection of gastrointestinal tissues for histopathological examination. Swabs were collected from various levels of the intestinal tract for aerobic, micro-aerobic and anaerobic culture and scrapings were collected for endoparasite evaluation by direct smear (performed by the Diagnostic Laboratory, Merck Research Laboratory). Samples were also submitted to MIT for micro-aerobic bacterial culture. Stools from five animals were tested for Giardia by ELISA ProSpectR Giardia Rapid Assay (Alexon-Trend, Ramsey, MN, USA), for Clostridium difficile toxins A and $\mathrm{B}$ at Cornell University Veterinary Diagnostic Laboratory with the Tox A/B kit (Techlab, Blacksburg, VA, USA) and for Shigella spp. by PCR (performed by Dr Hou-Shu Houng of the Walter Reed Army Institute of Research). Serum was taken from the six animals for haematology, clinical chemistry (Merck Diagnostic Laboratory) and viral serology, including herpes B virus, STLV, SRV and SIV (Bioreliance Laboratories). Evaluation of the two clinically normal monkeys consisted of collection of gastrointestinal tissue for culture and histopathological evaluation.

\section{Micro-aerobic culture}

Full-thickness colonic biopsy samples were collected at necropsy from anterior, transverse and descending portions of the large intestine. The samples were placed in brucella broth with glycerol $20 \%$ and frozen at $-70^{\circ} \mathrm{C}$ before micro-aerobic culture. After transport to MIT in dry ice, the samples were homogenised with phosphate-buffered saline (PBS). A portion of the tissue homogenate was passed through a $0.45-\mu \mathrm{m}$ filter and plated on to CVA medium (Remel Labs, Lenexa, $\mathrm{KS}$, USA) containing cefoperazone, vancomycin and amphotericin B, and helicobacter selective medium containing nalidixic acid, polymyxin $\mathrm{B}$, amphotericin $\mathrm{B}$, bacitracin and vancomycin. The remaining unfiltered homogenate was streaked on CVA or helicobacter selective medium. The cultures were incubated for 14 days in vented jars in an atmosphere of $80 \%, \mathrm{~N}_{2}, \mathrm{H}_{2}$ $10 \%$ and $\mathrm{CO}_{2} \quad 10 \%$. To analyse the bacteria biochemically, ultrastructurally, by $16 \mathrm{~S}$ rRNA sequencing and RFLP, cultures of bacteria compatible with Helicobacter spp. were subsequently passaged on sheep blood agar plates.

\section{Electron microscopy}

Three Helicobacter spp. isolates were examined after negative staining with a JEOL model JM 100EX transmission electron microscope operating at $100 \mathrm{kV}$. MIT 99-5503 and MIT 99-5504 (representing novel Helicobacter sp. rhesus type 1), and MIT 99-5512 (representing novel Helicobacter sp. rhesus type 2) were obtained from three different monkeys; the first two from control monkeys and the third from an animal with protracted diarrhoea. 


\section{Biochemical and physical characterisation of Helicobacter spp.}

Nine isolates from monkeys were subjected to a detailed biochemical characterisation as described previously [15]. The isolates were examined for catalase, oxidase and urease activities. The RapID NH System (Innovative Diagnostic Systems, Norcross, GA, USA) was used to examine the isolates for alkaline phosphatase hydrolysis, indoxyl acetate hydrolysis, gamma-glutamyl transpeptidase and hydrolysis of urea. The isolates were also tested for their ability to reduce nitrate with nitrate broth (Gibco Laboratories, Grand Island, NY, USA) and diagnostic reagents as described previously [2]. Growth was examined at $25^{\circ}$, $37^{\circ}$ and $42^{\circ} \mathrm{C}$ under aerobic, micro-aerobic and anaerobic conditions at 3-4 day intervals for up to 2 weeks. The organisms were also grown in the presence of glycine $1 \%$. Susceptibility to cephalothin $(30-\mu \mathrm{g}$ disk) and nalidixic acid (30- $\mu \mathrm{g}$ disk) was determined (Difco Laboratories, Detroit, MI, USA). The bacteria were also gram-stained and examined for motility in sterile PBS by phase contrast microscopy.

\section{DNA extraction}

DNA was extracted from growth on primary plates by InstaGene Matrix (BioRad Laboratories, Hercules, CA, USA). Bacteria were selected from CVA plates and resuspended in $1 \mathrm{ml}$ of double-distilled $\mathrm{H}_{2} \mathrm{O}$ in a microfuge tube. After centrifugation and removal of the supernate, $200 \mu \mathrm{l}$ of Instagene matrix was added to the pellet and incubated at $56^{\circ} \mathrm{C}$ for $30 \mathrm{~min}$. The samples were then boiled for $10 \mathrm{~min}$, centrifuged for $5 \mathrm{~min}$ at high speed and $10 \mu \mathrm{l}$ of the supernate were used for the PCR reaction.

\section{PCR amplification of bacterial isolates}

Helicobacter genus-specific primers C97 (5'-GCT ATG ACG GGT ATC C-3') and C05 (5'-ACT TCA CCC CAG TCG CTG-3') were used to amplify a 1200-bp PCR product from Helicobacter spp. Campylobacter genus-specific primers C98 (5'-GAT TTT ACC CC TAC ACC A-3') and C99 (5'-GCG TGG AGG ATG ACA CCT-3') were used to amplify a 298-bp PCR product from Campylobacter spp. PCR amplification reactions were performed with a thermal cycler and Taq polymerase (Roche Molecular Biochemical, Indianapolis, IN, USA). The reaction mixture (100 $\mu \mathrm{l})$ contained $1 \times$ polymerase buffer (supplied by the manufacturer but supplemented with $1 \mathrm{M} \mathrm{MgCl}_{2}$ to a final concentration of $2.25 \mathrm{mM}$ ), $0.5 \mu \mathrm{M}$ each of the two primers, $200 \mu \mathrm{M}$ of each deoxyribonucleotide and bovine serum albumin $200 \mu \mathrm{g} / \mathrm{ml}$. Samples were heated at $94^{\circ} \mathrm{C}$ for $4 \mathrm{~min}$, briefly centrifuged and cooled to $58^{\circ} \mathrm{C}$. $T a q$ polymerase $(2.5 \mathrm{U})$ was then added. Amplification was achieved by denaturation at $94^{\circ} \mathrm{C}$ for $1 \mathrm{~min}$, annealing at $58^{\circ} \mathrm{C}$ for $2 \mathrm{~min}$ and elongation at $72^{\circ} \mathrm{C}$ for $2 \mathrm{~min}$. A $15-\mu 1$ portion of the sample was then electrophoresed through a Visigel 6\% separation matrix (Stratagene, LaJolla, CA, USA).

\section{Amplification of $16 S$ rRNA cistrons from Helicobacter spp. by PCR and purification of PCR products}

Sequences of the 16S rRNA genes of five bacterial isolates (MIT 99-5501, 99-5504, 99-5507, 99-5512, 995513) were determined. The $16 \mathrm{~S}$ rRNA cistrons were amplified with eight sequencing primers used for Helicobacter spp. 16S rRNA and for intervening sequences present at Escherichia coli position 210 by methods described previously [16]. PCR was performed in thin-walled tubes with a Perkin-Elmer 9700 Thermocycler. One $\mu \mathrm{l}$ of the DNA template was added to a reaction mixture (50 $\mu \mathrm{l}$ final volume) containing 20 pmole of each primer, 40 nmole of dNTPs, 1 unit of Taq 2000 polymerase (Stratagene) in buffer containing Taqstart Antibody (Sigma Chemical Co.). In a hot start protocol, samples were preheated at $95^{\circ} \mathrm{C}$ for $8 \mathrm{~min}$ followed by amplification under the following conditions: denaturation at $95^{\circ} \mathrm{C}$ for $45 \mathrm{~s}$, annealing at $60^{\circ} \mathrm{C}$ for $45 \mathrm{~s}$ and elongation for $1.5 \mathrm{~min}$ with an additional $5 \mathrm{~s}$ for each cycle. A total of 30 cycles were performed and then followed by a final elongation step at $72^{\circ} \mathrm{C}$ for $10 \mathrm{~min}$. The results of PCR amplification were examined by electrophoresis in agarose $1 \%$ gel. DNA was stained with ethidium bromide and visualised under short wavelength UV light.

\section{$16 S$ rRNA sequencing}

Purified DNA from PCR was sequenced with an ABI Prism cycle-sequencing kit (BigDye ${ }^{\circledR}$ Terminator Cycle Sequencing kit with AmpliTaq DNA polymerase, FS, Perkin-Elmer). The primers used for sequencing were as described previously [17]. Quarter dye chemistry was used with $80-\mu$ mole of primers and $1.5 \mu \mathrm{l}$ of PCR product was used in a final volume of $20 \mu \mathrm{l}$. Cycle sequencing was performed with an $\mathrm{ABI}$ 9700 with 25 cycles of denaturation at $96^{\circ} \mathrm{C}$ for $10 \mathrm{~s}$, and annealing and extension at $60^{\circ} \mathrm{C}$ for $4 \mathrm{~min}$. Sequencing reactions were run on an ABI 377 DNA sequencer.

\section{$16 S$ rRNA data analysis}

Sequence data were entered into RNA, a programme set for data entry, editing, sequence alignment, secondary structure comparison, similarity matrix generation and dendrogram construction for 16S rRNA in Microsoft QuickBasic for use with PC computers, and were aligned as described previously [18]. The database contains $>1000$ sequences obtained in this laboratory and $>500$ obtained from GenBank. Dendrograms were constructed by the neighbour-joining method [19]. 


\section{Restriction fragment-length polymorphism of Helicobacter $16 S$ rRNA gene}

A 1.2-kb PCR fragment obtained from nine bacterial isolates from eight monkeys with Helicobacter genusspecific primers was subjected to restriction fragmentlength polymorphism (RFLP) analysis [20]. Amplified DNA $(20 \mu \mathrm{l})$ was digested with $10 \mathrm{U}$ of Alu I and Hha I in restriction buffer (New England Biolabs, Beverly, MA, USA) at $37^{\circ} \mathrm{C}$ for $3 \mathrm{~h}$. Restriction patterns were compared after the digested PCR products were separated in a Visigel 6\% separation matrix.

\section{Histopathology}

Colonic necropsy samples were fixed in neutral buffered formalin $10 \%$, processed by standard methods and embedded in paraffin. Then $5-\mu \mathrm{m}$ sections were stained with haematoxylin and eosin or Warthin-Starry silver stains. These sections were examined by light microscopy for evidence of lesions and for the presence of a bacterium with a morphology consistent with members of the genus Helicobacter.

\section{Nucleotide sequence accession numbers}

The 16S rRNA sequences for strains MIT 99-5501 and 99-5513 have been deposited in GenBank as AF333338 and AF333339. Sequences for strains MIT 99-5507, 99-5512 and 99-5513 were identical and have accession number AF333340.

\section{Results}

\section{Microbial analysis}

No single bacterial species was found in a majority of the animals, with the exception of Helicobacter spp. and E. coli. A Campylobacter sp. was isolated from two diarrhoeic monkeys. Tests for endoparasites, Giardia, C. difficile toxins and Shigella spp. by PCR were all negative (data not shown). Haematology and clinical chemistry parameters were within the normal range. All animals were serologically negative for the viruses tested.

\section{Isolation, growth, biochemical and physical characteristics of Helicobacter spp}

After incubation for 3-5 days, small pinpoint colonies developed on the agar surfaces. Helicobacter spp. were isolated from all three colonic (anterior, transverse, descending) biopsy samples from five monkeys (three with diarrhoea, two without) and from one of three colonic tissues from three other diarrhoeic monkeys. Bacteria were gram-negative and appeared spiral and motile under phase-contrast microscopy. The bacteria grew under micro-aerobic conditions at $37^{\circ} \mathrm{C}$ and $42^{\circ} \mathrm{C}$, but not $25^{\circ} \mathrm{C}$. Six isolates classified as type 1 were oxidase and catalase positive; all were urease negative.
The six isolates did not reduce nitrate nor hydrolyse alkaline phosphatase or indoxyl acetate, and they did not have gamma-glutamyl transpeptidase activity. They were also resistant to nalidixic acid and cephalothin. In contrast, three isolates classified as type 2 were oxidase positive, urease negative and weakly catalase positive. These bacteria were also distinguished from the type 1 strains by their ability to reduce nitrate and their sensitivity to cephalothin.

\section{Ultrastructure}

Cells had a spiral appearance and measured approximately $0.2 \mu \mathrm{m} \times 2-3 \mu \mathrm{m}$ (Fig. 1). They possessed bipolar, sheathed flagella.

\section{PCR identification of strains}

DNA from pure bacterial isolates was amplified with a Helicobacter genus-specific primer set. A $1.2-\mathrm{kb}$ fragment was amplified from 17 of the 24 bacterial isolates tested (Fig. 2).

\section{Phylogenetic analysis}

Full 16S rRNA sequences were obtained for five isolates from rhesus monkeys. Sequence lengths were $1490 \mathrm{bp}$ for four isolates and 1654 bp for MIT 99-5501, which contained an intervening sequence (IVS) of $164 \mathrm{bp}$. The IVS sequence was different from that of other helicobacter IVS, but typical in structure and location. With the exception of the IVS, sequences for MIT 99-5501 and MIT 99-5504 differed by only one bp and were $92-96 \%$ similar to most other helicobacter sequences. The closest sequence similarity, $97 \%$, is to a sequence from a Helicobacter isolate from a woodchuck, MIT 98-6070. This cluster was designated as Helicobacter sp. rhesus type 1. Each of these isolates was from a non-diarrhoeic monkey with moderate colitis noted on histological examination of the tissues.

The sequences for MIT 99-5507, MIT 99-5512 and MIT 99-5513 were identical. This cluster was designated as Helicobacter sp. rhesus type 2. All these isolates were from monkeys with diarrhoea. They are also $92-96 \%$ similar to most other helicobacter sequences. Sequences for rhesus type 2 isolates are $96 \%$ similar to several helicobacter sequences in our database, but they clustered loosely with $H$. fennelliae. Thus, based on a $16 \mathrm{~S}$ rRNA sequence difference of 3$4 \%$ from known Helicobacter species, the rhesus isolates represent two novel Helicobacter species (Fig. 3).

\section{RFLPS}

The isolates subjected to RFLP analysis gave two banding patterns with $A l u$ I which differentiated the two novel Helicobacter spp. (Fig. 4). Helicobacter strains MIT 99-5501 and 99-5504 had different RFLP patterns 

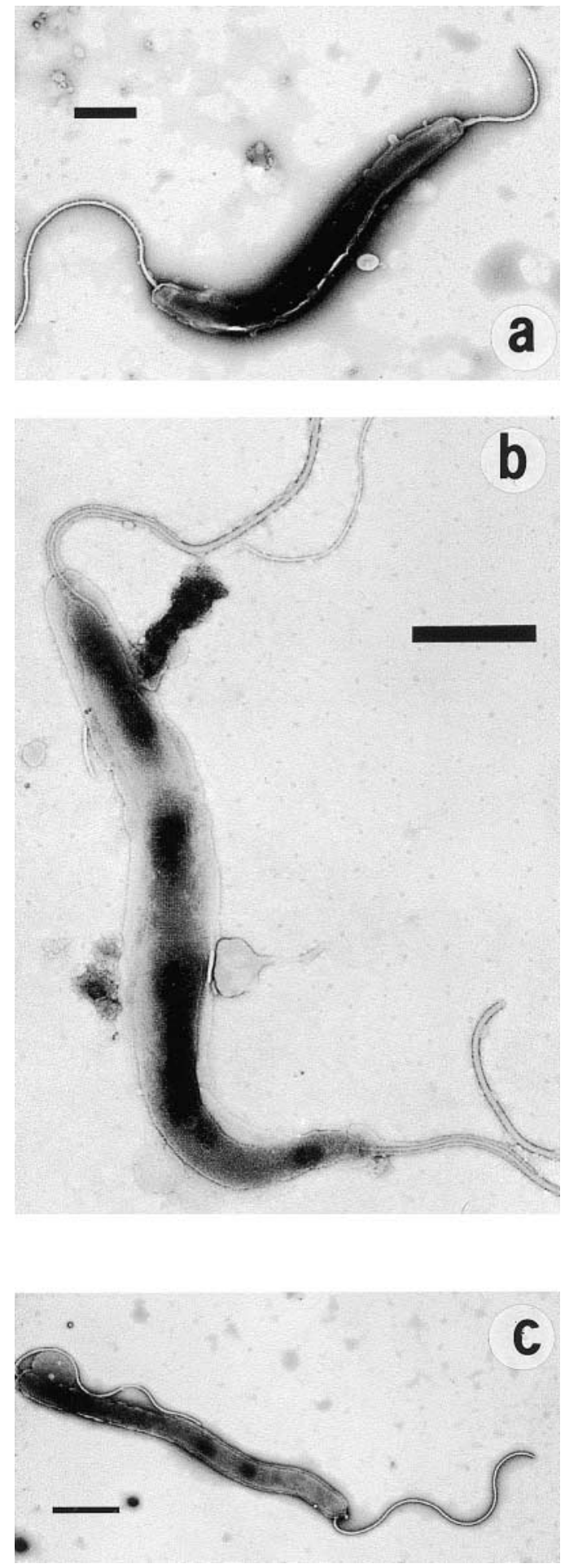

Fig. 1. Transmission electron micrograph of two novel Helicobacter spp. The cells had a spiral appearance and measured c. $0.2 \mu \mathrm{m} \times 2-3 \mu \mathrm{m}$; they possessed bipolar, sheathed flagella. (a) strain MIT 99-5503 (rhesus type 1); (b) strain MIT 99-5504 (rhesus type 1); (c) strain MIT 99-5512 (rhesus type 2). Bar $=0.5 \mu \mathrm{m}$.

because the IVS was present in strain 99-5501 and not in strain 99-5504. A fourth RFLP pattern was noted with one helicobacter $1.2-\mathrm{kb}$ PCR product. The identity of this organism is unknown at present. There were no discriminating differences in RFLP with Hha I.

\section{Histopathology}

Chronic colitis was observed in tissues from the nondiarrhoeic and diarrhoeic animals; however, the lesions were notably more intense in the diarrhoeic animals. In the diarrhoeic animals, colonic mucosal alterations were diffuse and characterised by moderate to marked degrees of mucosal hyperplasia and inflammation (Fig. 5). There was vascular congestion in segments of the colonic mucosa and the surface epithelium was irregular with swelling, flattening and loss of epithelial cells. The hyperplastic colonic crypts were elongated and lined by a hyperchromic epithelium with diminished goblet cell differentiation. Crypts were occasionally microcystic and contained necrotic epithelial and inflammatory cells. The inflammatory cell infiltrates were chiefly lymphoplasmacytic and histiocytic. Granulocytes were observed less frequently, usually in sites of epithelial cell disruption. In contrast, colonic tissues from the non-diarrhoeic animals were characterised by mild to moderate inflammation, typically mild mucosal hyperplasia, limited surface epithelial disruption and well-maintained goblet cell differentiation. Foci of necrotic inflammatory cells (including macrophages) were present in the superficial lamina propria, immediately beneath the surface epithelium of both diarrhoeic and non-diarrhoeic animals. Argyrophilic, spiral bacteria were observed in two primary patterns. Dense colonisation was observed along the surface and superficial crypt epithelium in samples from nondiarrhoeic animals. In these areas long, slender, spiral bacteria were distinguished at the edges of the dense colonies (Fig. 6). This pattern of colonisation was observed with segmental distribution in only two of the diarrhoeic animals. In addition to the absence of the dense surface colonisation, a different pattern of colonisation was observed in diarrhoeic animals, occupying the middle to deep zone of the colonic crypts. In this region, short spiral bacteria (Fig. 6) and longer, slender spiral bacteria were observed, which were not tightly associated with the crypt epithelium. Variably sized bacilli were also observed.

\section{Discussion}

This report describes, for the first time, the isolation of enteric helicobacters from macaques. The isolation of novel Helicobacter spp. from inflamed colons of diarrhoeic and non-diarrhoeic rhesus monkeys increases the number of Helicobacter spp. isolated from the intestines of animals and man to at least 15. Six of these enterohepatic helicobacters ( $H$. fennelliae, $H$. cinaedi, $H$. pullorum, $H$. canis, ' $H$. rappini' and $H$. canadensis) have been isolated from the faeces of diarrhoeic humans [17,21]. Phylogenetically, the two novel Helicobacters spp. isolated from rhesus monkeys with and without diarrhoea are clustered in a group of Helicobacter spp. with $H$. fennelliae which, like the two novel rhesus Helicobacter spp., is urease negative. 


\section{MW 1223445678910111213141516}

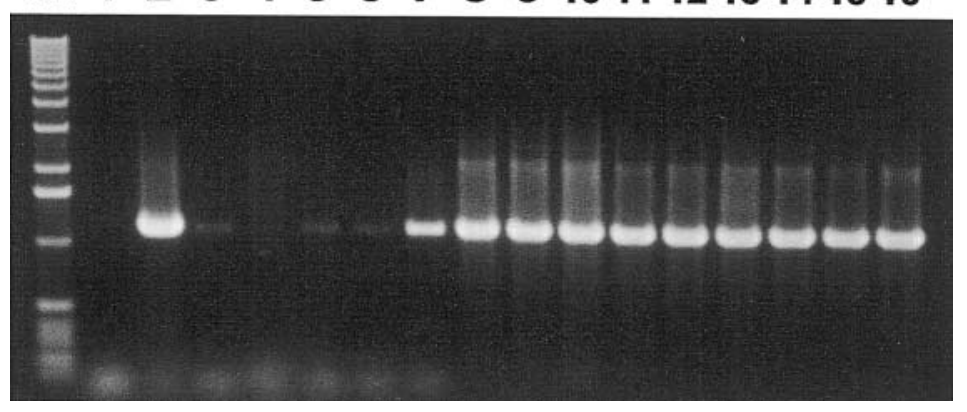

Fig. 2. PCR products of 14 isolates from six rhesus monkeys produced with Helicobacter genus-specific primers. Lane 1, reagent control; 2, H. hepaticus DNA was used as Helicobacter sp. positive control; 3-16, monkey isolates. All the isolates were positive for Helicobacter spp. except lane $\mathbf{4}$ which was a Campylobacter sp.

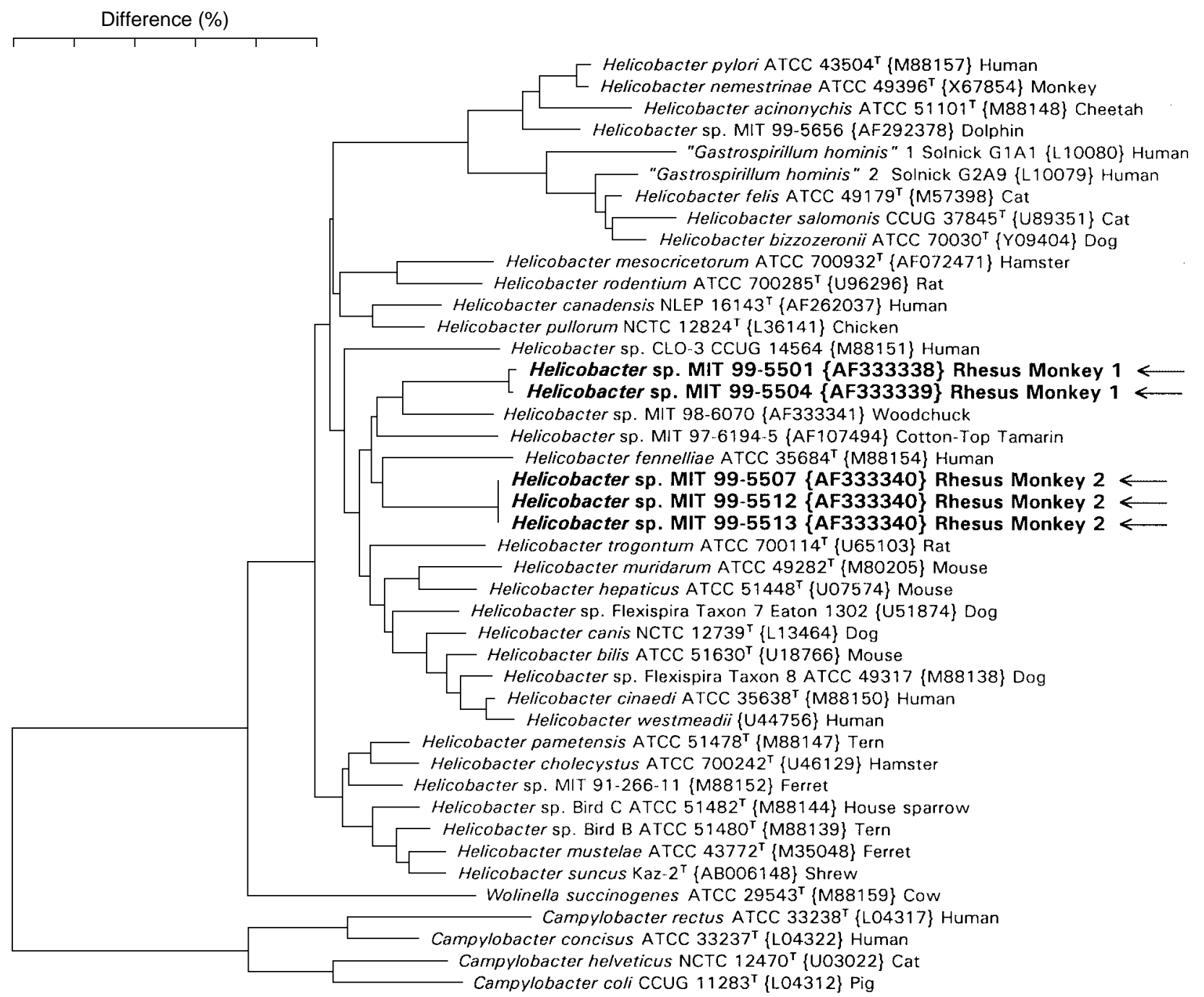

Fig. 3. Phylogenetic tree constructed on the basis of $16 \mathrm{~S}$ rRNA sequence similarity values. The scale bar is equal to a $5 \%$ difference in nucleotide sequences as determined by measuring the lengths of the horizontal lines connecting two species.

However, both urease-negative and urease-positive helicobacters have been isolated from intestinal tissue of animals; notably $H$. hepaticus and H. bilis, both urease-positive organisms, can induce typhlocolitis in rodents, whereas another two urease-negative novel
Helicobacter spp. have similar pro-inflammatory ability in rodents $[8,10,22,23]$. The novel Helicobacter sp. isolated from cotton top tamarins with ulcerative colitis is also urease negative, as is $H$. canis which has been isolated from diarrhoeic and non-diarrhoeic dogs and 
a

\section{$\begin{array}{llllllllll}M W & 1 & 2 & 3 & 4 & 5 & 6 & 7 & 8 & 9\end{array}$}

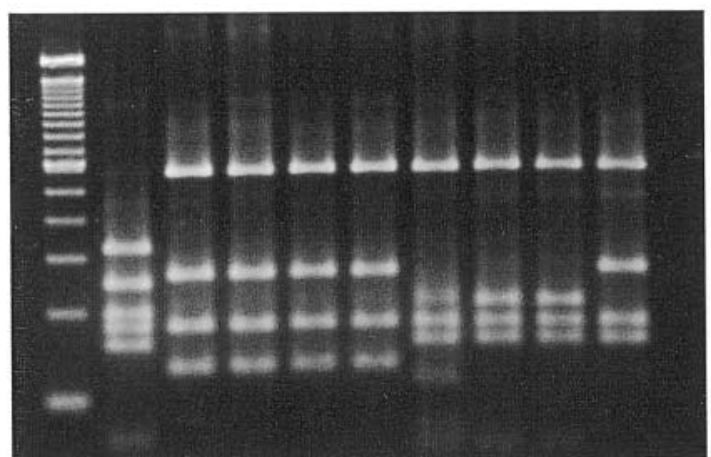

b

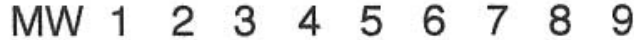

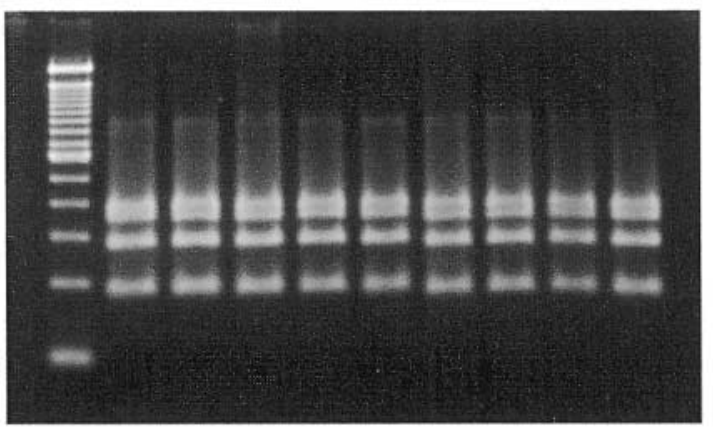

Fig. 4. PCR-RFLP patterns of $16 \mathrm{~S}$ rRNA gene from the monkey isolates. (a) DNA from monkey isolates digested by AluI; (b) DNA from monkey isolates digested by Hha I. The RFLP patterns of Helicobacter sp. rhesus type 1 and Helicobacter sp. rhesus type 2 can be distinguished by AluI digestion. Lanes 2-5, Helicobacter sp. rhesus type 2; 6-9, Helicobacter sp. rhesus type 1; lane 9 had an intervening sequence confirmed by $16 \mathrm{~S}$ rRNA sequence. Lane 1 had a different RFLP distinct from Helicobacter sp. Rhesus types 1 and 2. Hha I digestion produced the same pattern for all the monkey isolates.

cats $[2,24,25]$. These clinical and experimental data suggest that urease is not essential for eliciting inflammation in the large intestine $[2,8,24]$.

It is not known whether the novel Helicobacter spp. isolated in these clinically affected rhesus monkeys are the same spiral organisms previously identified histologically and by electron microscopy in clinically normal rhesus monkeys [26]. These authors described a natural infection in rhesus monkeys as intestinal spirochaetosis. Organisms observed by electron microscopy were embedded side by side in the brush border, with occasional penetration into the apical cytoplasm [26]. There was also loss of the glycocalyx, microvilli and terminal web of the colonic epithelia. These Warthin-Starry-positive organisms appeared by electron microscopy as two structurally different bacteria, one as a spirochaete, the other a spiral, flagellate bacterium [26]. The authors acknowledged that these organisms could somehow be involved in colitis and dysentery of
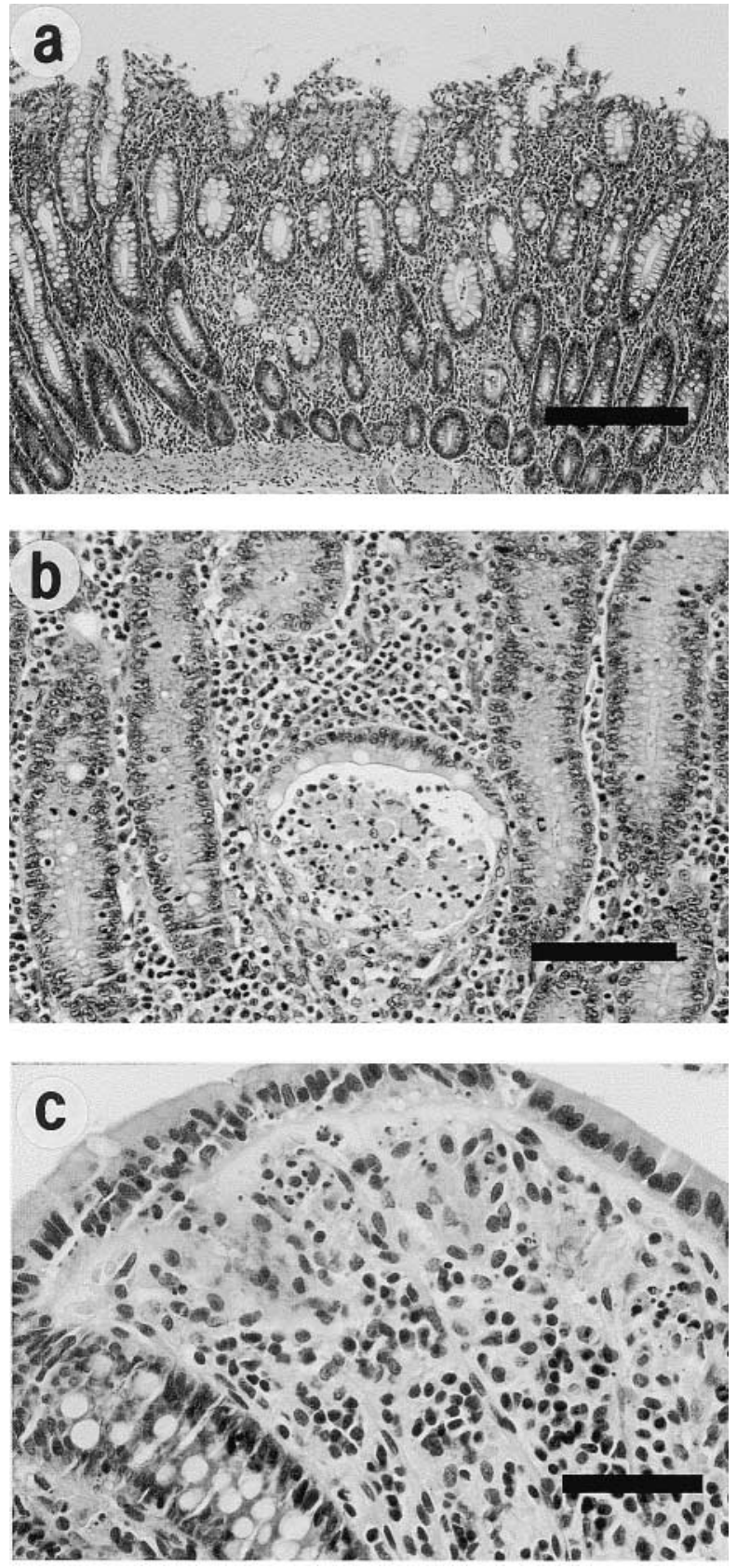

Fig. 5. Widespread multifocal superficial necrosis distorts the surface epthelium in diarrhoeic animals. There is a marked, diffuse, lymphoplasmacytic and histiocytic infiltrate in the lamina propria. The colonic crypts are elongated and hyperplastic and goblet cell density is diminished. Aggregates of necrotic cells are present in some crypts. Haematoxylin and eosin, bar $=200 \mu \mathrm{m}$.

undetermined aetiology. Clearly, the two novel Helicobacter spp. we examined by electron microscopy in the present study had spiral morphology and bipolar sheathed flagella. The diffuse pattern of brush border microbial colonisation along the surface epithelium and into the superficial crypts, as observed in the nondiarrhoeic animals, was disrupted or absent in the colonic sections from the diarrhoeic animals. The loss of surface colonisation was associated with the degeneration and necrosis of the surface epithelium in the diarrhoeic animals. Deeper colonisation within the 

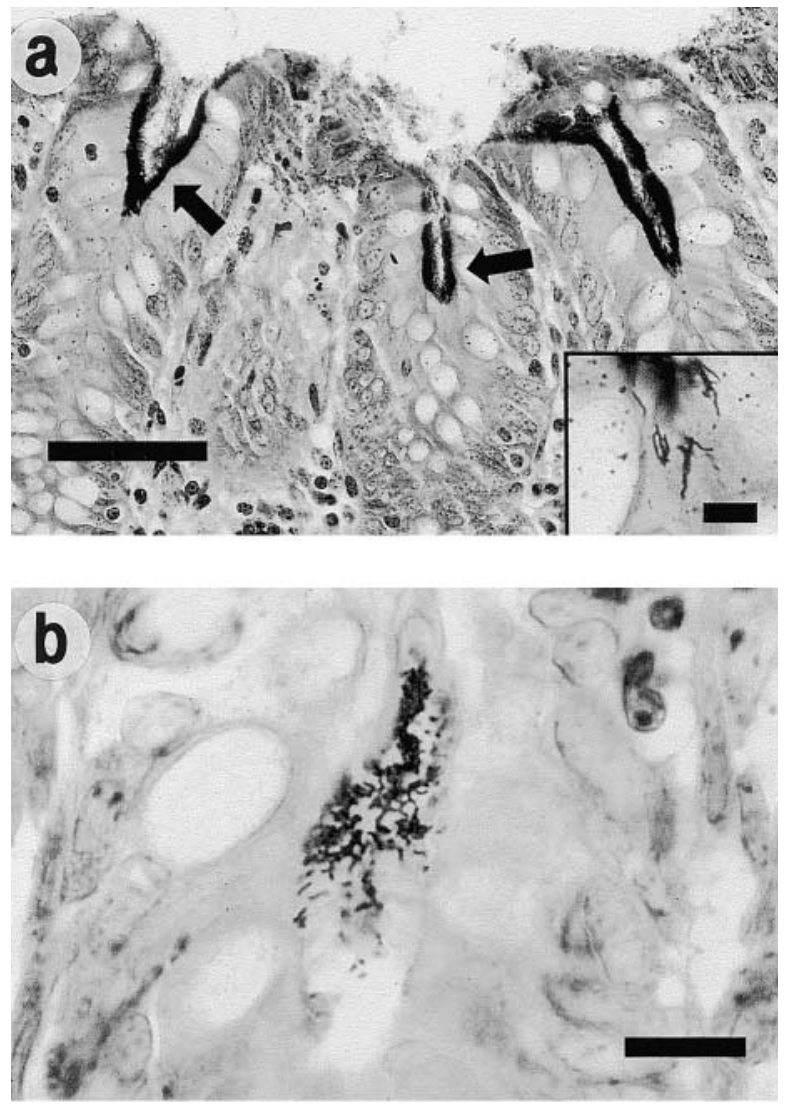

Fig. 6. (a) The non-diarrhoeic animals have prominent lamina of colonising bacteria on the surface epithelium, which extends into the superficial crypts. Warthin-Starry staining, bar $=50 \mu \mathrm{m}$. Inset: long, slender, spiral bacteria are bisible at the deep margin of the colonies. WarthinStarry staining, bar $=3 \mu \mathrm{m}$. (b) Aggregates of short, curved or spiral bacteria are also present in scattered crypts of diarrhoeic animals. Warthin-Starry staining, bar $=10 \mu \mathrm{m}$.

crypts by other bacteria, or a subset derived from the brush border flora, was also observed in the diarrhoeic animals. It should be noted that the surface colonisation in the non-diarrhoeic animals was also associated with a lower grade of colitis. In these animals, there were small foci of necrosis in the superficial lamina propria; however, there were limited epithelial alterations, as manifested in the diarrhoeic animals. Thus, both diarrhoeic and non-diarrhoeic monkeys had chronic colitis as well as colonisation with Helicobacter spp. It is tempting to speculate that - like $H$. pylori-induced gastritis where the majority of individuals with this infection are asymptomatic despite the presence of chronic inflammation - lower bowel helicobacter infection causes a chronic inflammation but only occasionally does the infection elicit clinical signs.

The clinical signs and pathological descriptions of the rhesus monkeys described in this report fulfill the criteria for a well known idiopathic syndrome in captive juvenile rhesus monkeys [1]. This chronic illness is classified as IBD or chronic colitis, and is differentiated from other causes of acute bacterial colitis where specific aetiological agents such as Campylobacter and Shigella spp. have been identified. In these types of acute colitis there is a scarcity of mononuclear inflammatory cells in the lamina propria and lack of mucosal hyperplasia and dysplastic glands [1]. The affected rhesus monkeys described in the present report did not have Shigella spp. identified, and Campylobacter spp. were present in only two of six diarrhoeic monkeys. In the majority of the idiopathic, chronic colitis cases seen in captive rhesus monkey colonies, the aetiology of the colitis is never determined. These animals suffer from a protracted episodic diarrhoea and weight loss, and eventually develop chronic colitis. Although the animals may initially respond to various antimicrobial agents, the diarrhoea recurs and becomes chronic. In this regard the disease is analogous to IBD in humans.

Although poorly defined, IBD is probably the result of a combination of genetic and environmental factors. Microbial flora are considered an important component of the IBD process in man, in which microbial antigens initiate and promote inflammation - particularly in the presence of immune dysregulation or an impaired mucosal barrier in the susceptible host [27-29].

With regard to a specific role for Helicobacter spp. in IBD, H. hepaticus, which induces a strong Th1 immune response, can cause IBD and hepatitis in $\mathrm{A} / \mathrm{JCr}$ and recombinant $\mathrm{AXB}$ mice as well as IBD in immune dysregulated rodents $[10,22,30]$. Although the causative role of a novel Helicobacter sp. isolated from CTT with ulcerative colitis has not been established, the systemic immune response to this helicobacter in infected monkeys is robust and appears to be specific $[2,7]$. Others investigating CTT ulcerative colitis by electron microscopy have noted a bacterium in affected colonic epithelia with the same morphology as that of the novel Helicobacter sp. isolated by Saunders et al. [2,31]. H. cinaedi and $H$. fennelliae have been associated with proctitis, colitis and diarrhoea in immunocompromised patients [12] and experimental studies demonstrated that these organisms can cause diarrhoea and bacteraemia in pig-tailed macaques [13]. Co-infection of Helicobacter spp. and Campylobacter spp. has also been recognised recently in both man and animals $[32,33]$. It is now known that C. jejuni and enterohepatic Helicobacter spp. express a cytolethal distending toxin $[34,35]$. Whether this toxin is in part responsible for tissue inflammation or otherwise affects the host immune response requires further investigation. Given these data, it is reasonable to hypothesise that the novel Helicobacter spp. isolated from rhesus monkeys in this report may play a role in the development and persistence of chronic colitis in these animals. However, further studies are warranted to elucidate the role of Helicobacter spp. in the development of idiopathic colitis in rhesus monkeys. 
This work was supported in part by NIH grants R01 DK 52413, CA67529 to JGF and DE10374 to F.E.D. We thank Dave Ngai and Walter Pouch for microbiology and parasitology support, and Edgar Brown and Marc Washington for haematological and serological analyses.

\section{References}

1. Adler RR, Moore PF, Schmucker DL, Lowenstine LJ. Chronic colitis, juvenile Macaca mulatta. In: Jones TC, Mohr U, Hunt RD (eds) Nonhuman primates II. New York, Springer-Verlag 1993: 81-87.

2. Saunders KE, Shen Z, Dewhirst FE, Paster BJ, Dangler CA, Fox JG. Novel intestinal Helicobacter species isolated from cotton-top tamarins (Saguinus oedipus) with chronic colitis. $J$ Clin Microbiol 1999; 37: 146-151.

3. Clapp NK, Henke MA, Hansard RM, Carson RL, Adams LJ, Nardi RV. Natural history, time course, and pathogenesis of idiopathic colitis in cotton-top tamarins Saguinus oedipus. In: Clapp NK (ed) A primate model for the study of colitis and colonic carcinoma: the cotton-top tamarin (Saguinus oedipus). Boca Raton, CRC 1993: 83-100.

4. Johnson LD, Ausman LM, Sehgal PK, King NW. A prospective study of the epidemiology of colitis and colon cancer in cotton-top tamarins (Saguinus oedipus). Gastroenterology 1996; 110: 102-115.

5. Kirkwood JK, Pearson GR, Epstein MA. Adenocarcinoma of the large bowel and colitis in captive cotton-top tamarins Saguinus O. oedipus. J Comp Pathol 1986; 96: 507-515.

6. Bertone ER, Giovannucci EL, King NW, Petto AJ, Johnson LD. Family history as a risk factor for ulcerative colitis-associated colon cancer in cotton-top tamarin. Gastroenterology 1998; 114: $669-674$.

7. Whary MT, Saunders KE, Esteves MI, Wood J, Peck OC, Fox JG. A novel Helicobacter sp. isolated from inflamed colonic tissue in cotton top tamarins is associated with a specific humoral immune response. Gastroenterology 1999; 116: A845.

8. Fox JG, Gorelick PL, Kullberg MC, Ge Z, Dewhirst FE, Ward JM. A novel urease-negative Helicobacter species associated with colitis and typhlitis in IL-10-deficient mice. Infect Immun 1999; 67: 1757-1762.

9. Kullberg MC, Ward JM, Gorelick PL et al. Helicobacter hepaticus triggers colitis in specific-pathogen-free interleukin10 (IL-10) deficient mice through an IL-12- and gamma interferon-dependent mechanism. Infect Immun 1998; 66: 5157-5166.

10. Cahill RJ, Foltz CJ, Fox JG, Dangler CA, Powrie F, Schauer DB. Inflammatory bowel disease: an immunity mediated condition triggered by bacterial infection with Helicobacter hepaticus. Infect Immun 1997; 65: 3126-3131.

11. Haines DC, Gorelick PL, Battles JK et al. Inflammatory large bowel disease in immunodeficient rats naturally and experimentally infected with Helicobacter bilis. Vet Pathol 1998; 35: 202-208.

12. Totten PA, Fennell CL, Tenover FC et al. Campylobacter cinaedi (sp. nov.) and Campylobacter fennelliae (sp. nov.): two new Campylobacter species associated with enteric disease in homosexual men. J Infect Dis 1985; 151: 131-139.

13. Flores BM, Fennell CL, Kuller L, Bronsdon MA, Morton WR, Stamm WE. Experimental infection of pig-tailed macaques (Macaca nemestrina) with Campylobacter cinaedi and Campylobacter fennelliae. Infect Immun 1990; 58: 3947-3953.

14. Reindel JF, Fitzgerald AL, Breider MA et al. An epizootic of lymphoplasmacytic gastritis attributed to Helicobacter pylori infection in cynomolgus monkeys (Macaca fascicularis). Vet Pathol 1999; 36: 1-13.

15. Shen Z, Fox JG, Dewhirst FE et al. Helicobacter rodentium sp. nov., a urease-negative Helicobacter species isolated from laboratory mice. Int J Syst Bacteriol 1997; 47: 627-634.
16. Fox JG, Yan LL, Dewhirst FE et al. Helicobacter bilis sp. nov., a novel Helicobacter isolated from bile, livers, and intestines of aged, inbred mice. J Clin Microbiol 1995; 33: 445-454.

17. Fox JG, Chien CC, Dewhirst FE et al. Helicobacter canadensis sp. nov. isolated from humans with diarrhea as an example of an emerging pathogen. J Clin Microbiol 2000; 38: 2546-2549.

18. Paster BJ, Dewhirst FE. Phylogeny of Campylobacter, wolinellas, Bacteroides gracilis, and Bacteroides ureolyticus by $16 \mathrm{~S}$ ribosomal ribonucleic acid sequencing. Int $J$ Syst Bacteriol 1988; 38: 56-62.

19. Saitou N, Nei M. The neighbor-joining method: a new method for reconstructing phylogenetic trees. Mol Biol Evol 1987; 4: $406-425$.

20. Fox JG, Dewhirst FE, Shen $\mathrm{Z}$ et al. Hepatic Helicobacter species identified in bile and gallbladder tissue from Chileans with chronic cholecystitis. Gastroenterology 1998; 114: 755763.

21. Fox JG, Lee A. The role of Helicobacter species in newly recognized gastrointestinal tract diseases of animals. Lab Anim Sci 1997; 47: 222-255.

22. Whary MT, Morgan TJ, Dangler CA, Gaudes KJ, Taylor NS, Fox JG. Chronic active hepatitis induced by Helicobacter hepaticus in the $\mathrm{A} / \mathrm{JCr}$ mouse is associated with a Th1 cellmediated immune response. Infect Immun 1998; 66: $3142-$ 3148 .

23. Shomer NH, Dangler CA, Marini R, Fox JG. Helicobacter bilis/Helicobacter rodentium co-infection associated with diarrhea in a colony of scid mice. Lab Anim Sci 1998; 48: 455459.

24. Foley JE, Marks SL, Munson L et al. Isolation of Helicobacter canis from a colony of Bengal cats with endemic diarrhea. $J$ Clin Microbiol 1999; 37: 3271-3275.

25. Stanley J, Linton D, Burnens AP et al. Helicobacter canis sp. nov., a new species from dogs: an integrated study of phenotype and genotype. J Gen Microbiol 1993; 139: 24952504.

26. Zeller J, Takeuchi A. Infection of the colon of the rhesus monkey by spiral-shaped organisms. Vet Pathol 1982; 19 Suppl 7: $26-32$.

27. Montgomery SM, Morris DL, Pounder RE, Wakefield AJ. Paramyxovirus infections in childhood and subsequent inflammatory bowel disease. Gastroenterology 1999; 116: 796-803.

28. Fiocchi C. Inflammatory bowel disease: etiology and pathogenesis. Gastroenterology 1998; 115: 182-205.

29. Panwala CM, Jones JC, Viney JL. A novel model of inflammatory bowel disease: mice deficient for the multiple drug resistance drug resistance gene, mdrla, spontaneously develop colitis. J Immunol 1998; 161: 5733-5744.

30. Ihrig M, Schrenzel MD, Fox JG. Differential susceptibility to hepatic inflammation and proliferation in AXB recombinant inbred mice chronically infected with Helicobacter hepaticus. Am J Pathol 1999; 155: 571-582.

31. Chalifoux LV, Bronson RT, Escajadillo A, McKenna S. An analysis of the association of gastroenteric lesions with chronic wasting syndrome of marmosets. Vet Pathol 1982; 19 Suppl 7: $141-162$.

32. Shen Z, Feng Y, Fox JG. Co-infection with enteric Helicobacter spp. and Campylobacter spp. in asymptomatic cats. Lab Anim Sci 1999; 49: 434.

33. Allos BM, Lastovica AJ, Blaser MJ. Atypical campylobacters and related microorganisms. In: Blaser MJ, Smith PD, Ravdin JI, Greenberg HB, Guerrant RL (eds) Infections of the gastrointestinal tract. New York, Raven Press. 1995: 849-865.

34. Chien C-C, Taylor NS, Ge Z, Schauer DB, Young VB, Fox JG. Identification of $c d t \mathrm{~B}$ homologues and cytolethal distending toxin activity in enterohepatic Helicobacter spp. $J$ Med Microbiol 2000; 49: 525-534.

35. Pickett CL, Pesci EC, Cottle DL, Russell G, Erdem AN, Zeytin $\mathrm{H}$. Prevalence of cytolethal distending toxin production in Campylobacter jeuni and relatedness of Campylobacter sp. $c d t B$ genes. Infect Immun 1996; 64: 2070-2078. 